\title{
Zastosowanie metody K-Ar do oznaczenia wieku deformacji skał metaosadowych formacji Yargait terranu Zavkhan (Khasagt, Mongolia) - wstępne wyniki badań
}

\author{
Rafał Sikora $^{1}$, Antoni Wójcik ${ }^{1}$, Marek Szczerba ${ }^{2}$, Jakub Bazarnik $^{1}$, Stanisław Madej $^{3}$
}

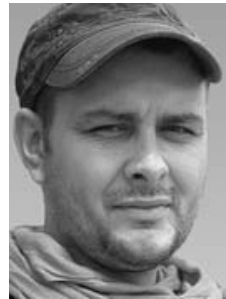

R. Sikora

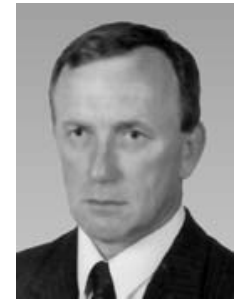

A. Wójcik

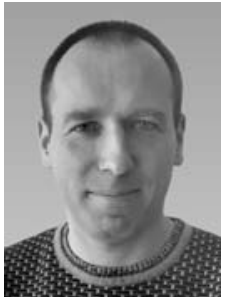

M. Szczerba

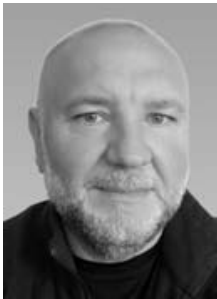

S. Madej

K-Ar dating of deformation of metasedimentary rocks from the Yargait Formation of the Zavkhan terrane (Khasagt Mountains, Mongolia) - preliminary results. Prz. Geol., 69: 448-453; doi: 10.7306/2021.29

A b s tract. The SW margin of the Zavkhan terrane is significant for research on Paleozoic amalgamation of the Central Asian Orogenic Belt (CAOB). The study area is located in the western part of the Khasagt Mountains, western Mongolia. We present a new preliminary $\mathrm{K}-\mathrm{Ar}$ dating of metasedimentary rocks from the Yargait Formation which were deformed during collision of the Zavkhan terrane with the Lake Zone terrane. Our results include two dating that are similar to earlier data by other authors (Štipská et al., 2010; Bold et al., 2016b). The first dating equal to $544.1 \pm 13.7 \mathrm{Ma}$ can be interpreted as the age of metamorphism and the subduction of the SW margin of the Zavkhan terrane under the Lake Zone terrane during the late Ediacaran-early Cambrian. The second dating of $441.1 \pm 11.7$ Ma indicates the Late Ordovician - Silurian regional extension event.

Keywords: K-Ar dating, muscovite, tectonics, Zavkhan terrane, Mongolia, Central Asian Orogenic Belt

Metoda datowania K-Ar jest stosowana do określania wieku bezwzględnego minerałów zawierających potas, takich jak np.: muskowit, biotyt, illit, glaukonit lub skaleń potasowy. Uzyskiwany wiek może odpowiadać temperaturze zamknięcia, jak w przypadku biotytu, bądź krystalizacji, jak dla illitu. Przedstawione w artykule wyniki datowań metodą K-Ar wykorzystano w celu określenia wieku metamorfizmu i przebudowystrukturalnej skał metaosadowych na SW krawędzi terranu Zavkhan (Dzabkhan, Dzawchan). Metodę tę z sukcesem zastosowano w ostatnich latach do badań skał niskotemperaturowych (m.in. Clauer i in., 2012; Kowalska, 2012; Fitz-Diaz, van der Pluijm, 2013). Terran Zavkhan jest jednym z 44 proterozoicznych kratonicznych terranów lub mikrokontynentów (Lehmann i in., 2010) wyróżnionych w mongolskiej części środkowoazjatyckiego pasa orogenicznego (Central Asian Orogenic Belt CAOB; Badarch i in., 2002). Skały znajdujące się w krawędziowej SW części terranu odsłaniają się na terenie Gór Khasagt w zachodniej Mongolii, które rozciągają się w kierunku NW-SE na przestrzeni ok. $120 \mathrm{~km}$ na zachód od miejscowości Ałtaj (ryc. 1A). Rozpoznanie zasadniczych rysów struktury Khasagtu było wynikiem prac polskiej ekspedycji w latach 60. XX w. (Don, Dumicz, 1964; Dumicz, Don, 1970; Rutkowski i in., 1970). Mapa geologiczna tego obszaru w skali 1 : 50000 została opracowana na przełomie XX i XXI w. (Enkhbayar i in., 2005) i uszczegółowiona w latach 2009-2013 (Wójcik i in., 2015).

\section{ZARYS GEOLOGII REGIONU}

Pod względem tektonicznym terran Zavkhan jest zlokalizowany na północ od głównego lineamentu mongolskiego (ryc. 1A), który stanowi regionalną dyslokację przesuwczą oddzielającą znajdujący się na północy obszar o konsolidacji kaledońskiej od położonej na południu strefy waryscyjskiej (ałtajskiej). Akrecyjny model ewolucji CAOB (Badarch, 2002; Windley i in., 2007) zakłada, że obszar północny to terrany perysyberyjskie, a południowy - okołogondwańskie. Syberyjskie pochodzenie cokołu mikrokontynentu zavkhańskiego sugeruje również koncepcja łuku perysyberyjskiego (Şengör i in., 1993; Tomurtogoo i in., 2005; Cocks, Torsvik, 2007; Wilhem i in., 2012). Według scenariusza zakładającego kolizję terranów egzotycznych terran Zavkhan jest pochodzenia okołogondwańskiego (Mossakovsky i in., 1994; Kröner i in., 2010, 2014). Za modelem kolizyjnym przemawiają też badania Bold $\mathrm{i}$ in. (2016b). W tym ujęciu terran Zavkhan ma też związek z paleozoicznym, akrecyjnym, tzw. mongolskim kontynentem wstęgowym (Mongolian ribbon continent), który uległ kolizji z Syberią w kambrze, a następnie w mezozoiku (van der Voo i in., 2015; Kilian i in., 2016) lub na początku paleozoiku był położony blisko niej, a wydarzenia tektoniczne na obu kontynentach były zbieżne.

Dotychczasowe dane na temat ewolucji terranu Zavkhan opierają się głównie na analizach kartograficznych, stratygraficznych, paleontologicznych, paleomagnetycznych

\footnotetext{
${ }^{1}$ Państwowy Instytut Geologiczny - Państwowy Instytut Badawczy, Centrum Geozagrożeń, ul. Skrzatów 1, 31-560 Kraków; rafal.sikora@pgi.gov.pl

${ }^{2}$ Instytut Nauk Geologicznych PAN, ul. Senacka 1, 31-002 Kraków; m.szczerba@ingpan.krakow.pl

${ }^{3}$ Instytut Nauk Geologicznych, Uniwersytet Wrocławski, pl. Maksa Borna 9, 50-204 Wrocław; stanislaw.madej@uwr.edu.pl
} 


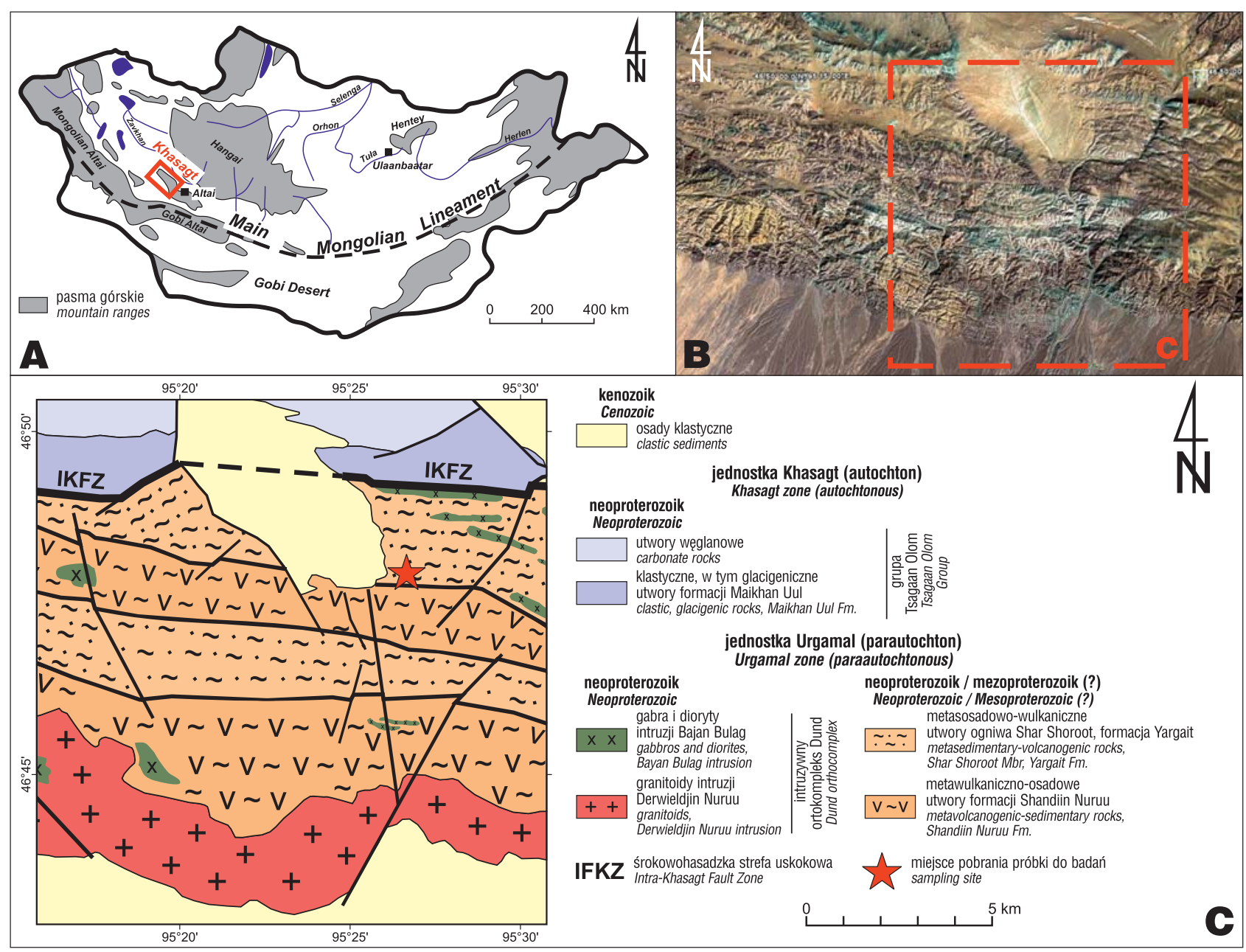

Ryc. 1. A - położenie Gór Khasagt na tle głównych pasm górskich w Mongolii, B - lokalizacja terenu badań na tle rzeźby zachodniej części Gór Khasagt (źródło: google.com), C - mapa geologiczna rejonu badań (na podstawie Wójcika i in., 2015, zmienione)

Fig. 1. A - Khasagt Mountains against the backdrop of mountain ranges of Mongolia, $\mathbf{B}$ - location of the research area against the relief of the western part of Khasagt Mts. (source: google.com), C - geological map of the study area (based on Wójcik et al., 2015, modified)

i datowaniach radiometrycznych cyrkonów (Togtokh i in., 1995; Burashnikov, 1990; Ruzhnetsev, Burashnikov, 1996; Enkhbayar i in., 2005; Zhao i in., 2006; Macdonald i in., 2009; Kozakov i in., 2012; Bold i in., 2016a, b; Kilian i in., 2016; Smith i in., 2016). Do tej pory nie publikowano wyników szczegółowych badań strukturalnych, które można wykorzystać w modelu geodynamicznym rozwoju terranu Zavkhan i jego relacji z terranami sąsiednimi. Były one jedynie sygnalizowane na konferencjach tematycznych (Sikora i in., 2016, 2019; Sikora, Wójcik, 2017).

Na obszarze badań wyróżnia się dwie jednostki tektoniczne, które kontaktują ze sobą wzdłuż ważnej strefy tektonicznej nawiązującej do przebiegu uskoków Bayanbogd Hoyor, Onder Ulaan i Huron Showhyn (Enkhbayar i in., 2005; Sikora, 2015). Istnienie w tej strefie jednego z głównych uskoków w regionie stwierdzili również Bold i in. (2016b). Ze względu na duże znaczenie tych dyslokacji w strukturze regionu proponujemy określenie ich mianem środkowokhasadzkiej strefy uskokowej (Intra-Khasagt Fault Zone-IKFZ; ryc. 1C). Po jej północno-wschodniej stronie znajduje się autochtoniczna jednostka Khasagt (Ruzhnetsev, Burashnikov, 1996; Enkhbayar i in., 2005; Wójcik $\mathrm{i}$ in., 2015; Bold i in., 2016b; Sikora i in., 2016, 2019). Najwyższą część krystalicznego podłoża tej jednostki stanowią metawulkano-klastyczne utwory formacji Zavkhan, a na jej pokrywę osadową składają się skały neoproterozoiczno-kambryjskiej grupy Tsagaan Olom (ryc. 1C). Od południowego zachodu poprzez IKFZ na jednostkę autochtoniczną jest nasunięta parautochtoniczna jednostka Urgamal (Badarch i in., 2002), złożona głównie ze skał metamorficznych i magmowych. Z kolei na parautochton od południowego zachodu nasunięte są maficzne i ultramaficzne elementy allochtoniczne terranu strefy jeziornej (Lake Zone terrane; Ruzhnetsev i Burashnikov, 1996; Enkhbayar i in., 2005; Wójcik i in., 2015; Bold i in., 2016b; Sikora i in., 2016, 2019). Wychodnie tej jednostki znajduja się poza obszarem badań. Główne fałdowo-nasuwcze procesy na SW krawędzi terranu Zavkhan zakończyły się w kambrze, wraz z zamknięciem basenu Tsagaan Olom (Enkhbayar i in., 2005; Wójcik i in., 2015; Bold i in., 2016b; Sikora i in., 2016). Nie jest dokładnie określony wpływ wczesnopaleozoicznych procesów tektonicznych na zmiany metamorficzne skał jednostki Urgamal, jak również ich relacja ze strukturami zapisanymi w skałach grupy Tsagaan Olom.

\section{TEKTONIKA I LITOSTRATYGRAFIA JEDNOSTKI URGAMAL}

Do jednostki Urgamal zalicza się kilka różnowiekowych (od paleoproterozoiku po neoproterozoik; ryc. 1C) 
formacji złożonych ze skał o różnym stopniu zmetamorfizowania. Najstarszymi utworami podłoża krystalicznego są ortognejsy, paragnejsy i kwarcyty kompleksu Khavchig (Togtokh i in., 1995). Posiadają one zapis metamorfizmu facji amfibolitowej do granulitowej. Gnejsy kompleksu Khavchig wykazują różny wiek $849 \pm 9$ Ma (Zhao i in., 2006), $856 \pm 2 \mathrm{Ma}$ (Kozakov i in., 2012) oraz $1967 \pm 13 \mathrm{Ma}$ (Bold i in., 2016b). Przedmiotem badań są, znajdujące się wyżej w profilu litostratygraficznym, skały metaosadowe (fyllity i łupki łyszczykowe facji zieleńcowej) ogniwa Shar Shoroot formacji Yargait (Togtokh i in., 1995; ryc. 2), które obok skał metosadowo-wulkanicznej formacji Shandiin nuruu (m.in. ryolity, doleryty i bazalty; Enkhbayar i in., 2005) stanowią osłonę ortokompleksu Dund (Ruzhnetsev, Burashnikov, 1996; Bold i in., 2016b). Bold i in. (2016) przypisują im wiek neoproterozoiczny, a Enkhbayar $\mathrm{i}$ in. (2005) zaliczaja je do mezoproterozoiku. W skład ortokompleksu Dund wchodzą gabra, dioryty intruzji Bayan Bulag i granitoidy intruzji Derweldjin Nuruu oraz ryolity intruzji Bayan Bogd (Enkhbayar i in., 2005; Wójcik i in., 2015). Dioryty kompleksu Dund są datowane na $811,36 \mathrm{Ma}$ (Bold i in., 2016a). Wójcik i in. (2019) określili wiek granitoidów na $816 \pm 3,9$ do $774,9 \pm 4,8 \mathrm{Ma}$, a ryolitów na $784,1 \pm 6,9 \mathrm{Ma}$.

\section{BADANIA ZA POMOCA ANALIZY DYFRAKCYJNEJ I DATOWANIE METODĄ K-Ar}

Po przeprowadzeniu petrograficznych badań mikroskopowych, do dalszych analiz wytypowano próbkę łupka kwarcowo-muskowitowo-chlorytowego z ogniwa Shar Shoroot formacji Yargait. Skład mineralny wybranej próbki i jej frakcji 2,0-0,2 i <0,2 $\mu$ m określono metoda analizy dyfrakcyjnej na preparatach dezorientowanych (ładowanych bocznie), wykonanych ze zmielonych próbek proszkowych. Pomiary wykonano na dyfraktometrze Thermo ARL X'TRA wyposażonym w lampę $\mathrm{Cu}$ w zakresie 5-65 $2 \Theta$ (3 sek. na krok $\left.0,02^{\circ} 2 \Theta\right)$, znajdującym się w Instytucie Nauk Geologicznych PAN. Do analizy ilościowej wykorzystano oprogramowanie Q-Min, które używa bazy wzorców minerałów, zarejestrowanych wcześniej na tym samym dyfraktometrze.

Całą próbkę i jej frakcje 2,0-0,2 i <0,2 $\mu$ m zawierające muskowit datowano metodą K-Ar w celu ustalenia wieku krystalizacji tego minerału i sprawdzenia udziału muskowitu detrytycznego. Zawartość potasu mierzono za pomoca fotometru płomieniowego Sherwood Model 420. Pomiary radiogenicznego argonu wykonano na wielokolektorowym spektrometrze gazów szlachetnych $\mathrm{Nu}$ Instruments Noblesse. Każda próbka została stopiona za pomocą lasera

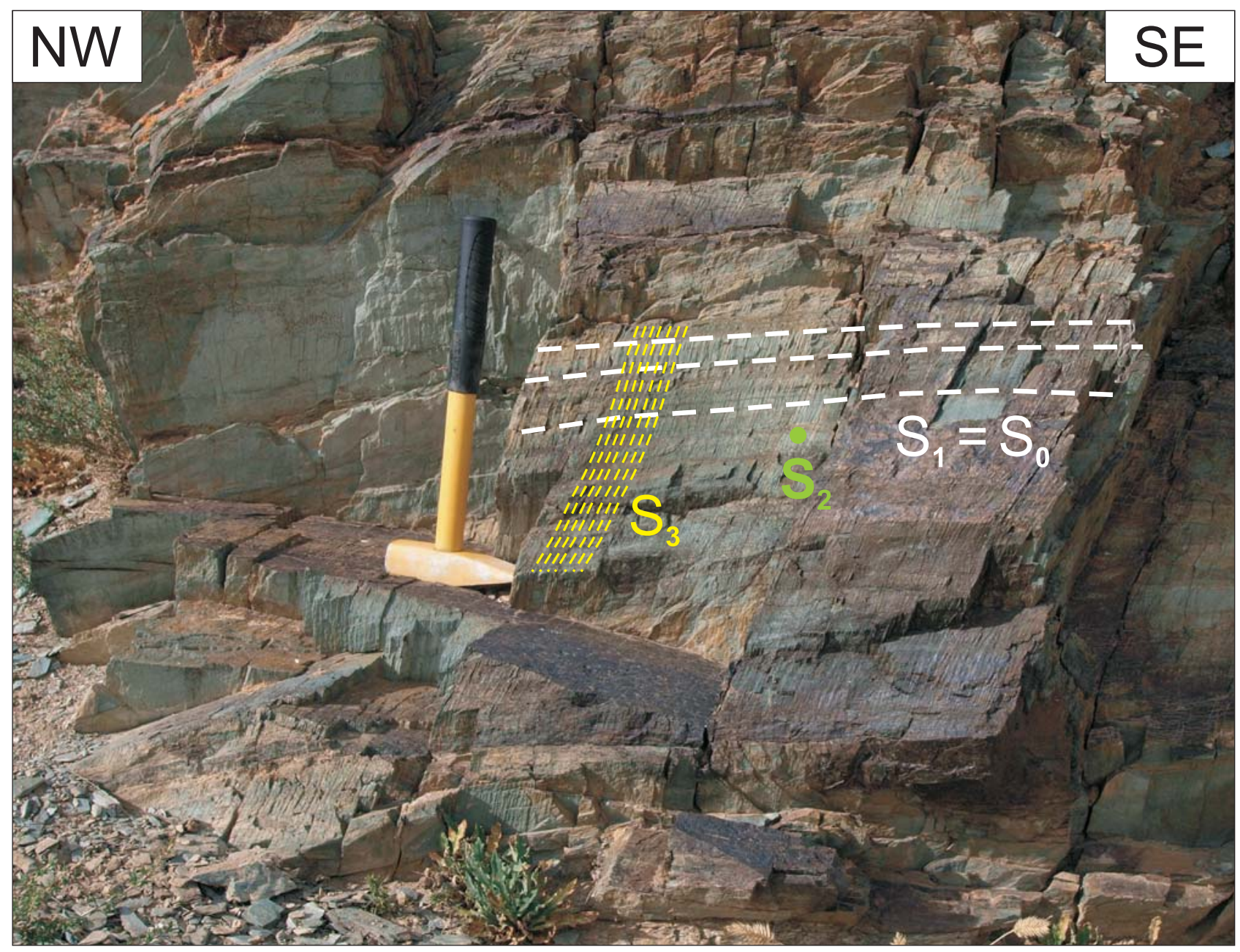

Ryc. 2. Odsłonięcie łupków kwarcowo-muskowitowo-chlorytowych ogniwa Shar Shoroot (formacja Yargait) z wyraźnie widoczną superpozycją foliacji metamorficznej S1, skośnego złupkowacenia S2 i prostopadłego S3. Widok w kierunku NE

Fig. 2. Outcrop of the Shar Shoroot Member (Yargait Formation) slates with clearly visible superposition of the metamorphic foliation $\mathrm{S} 1$, the oblique slaty cleavage S2 and the perpendicular slaty cleavage S3. View is to the NE 


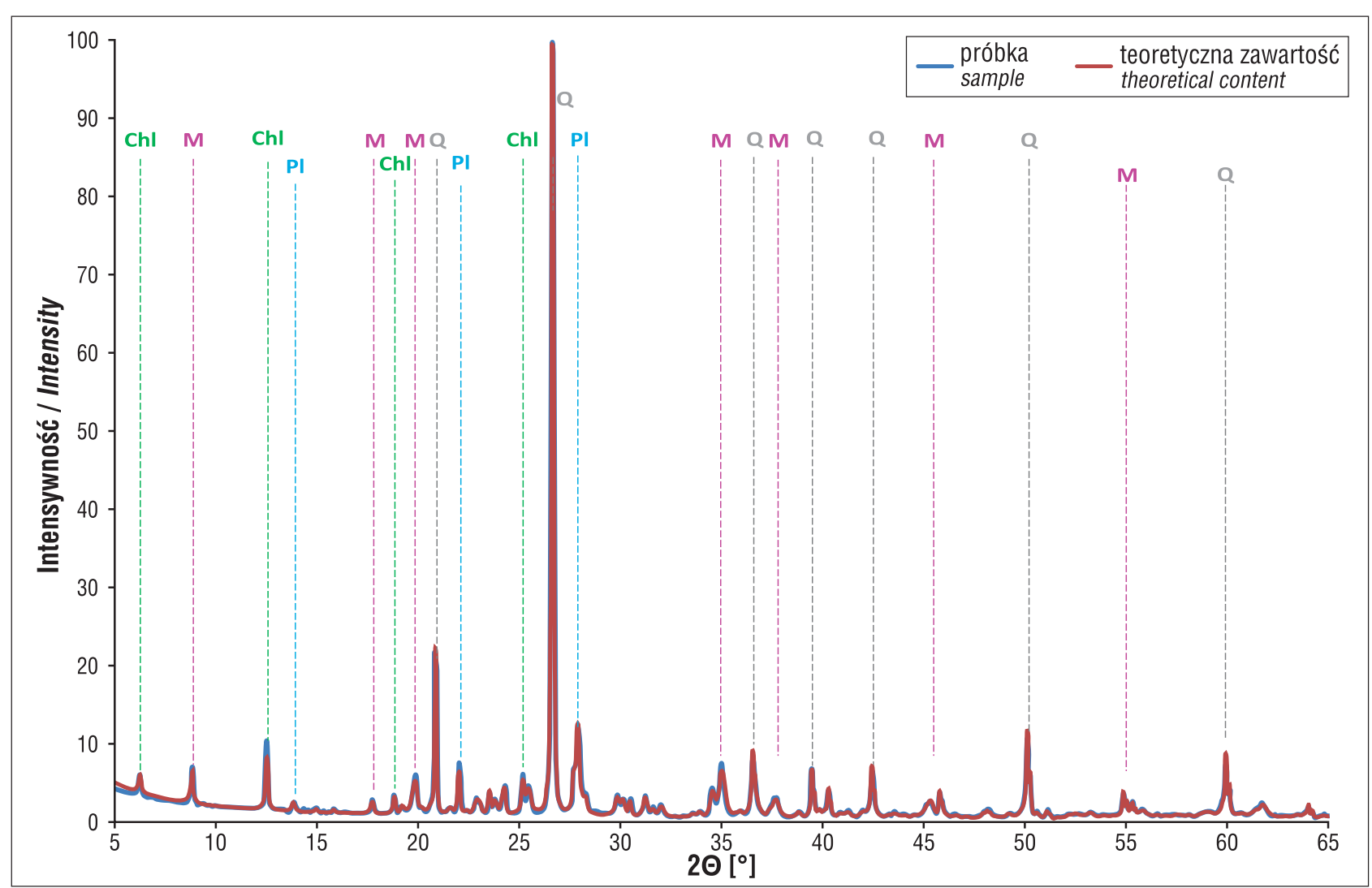

Ryc. 3. Dyfraktogram badanej próbki (linia niebieska) w porównaniu do sumy dyfraktogramów poszczególnych minerałów (linia czerwona) w zakresie 5-65 $2 \Theta$. M - muskowit, $\mathbf{Q}$ - kwarc, $\mathbf{P I}$ - plagioklaz, Chl - chloryt

Fig. 3. Diffractogram of the analyzed sample (blue line) in comparison to the line showing the sum of diffractograms of individual minerals (red line) in the range of 5-65 $2 \Theta$. $\mathbf{M}$ - muscovite, $\mathbf{Q}$ - quartz, $\mathbf{P I}$ - plagioclase, $\mathbf{C h l}$ - chlorite

podczerwonego $972 \mathrm{~nm}$. Oczyszczanie gazów przeprowadzono za pomoca tytanowego gettera sublimacyjnego oraz gettera Z-100 (SAES Getters). Pomiary kalibrowano do międzynarodowego standardu GLO (Odin, 1982), z wykorzystaniem spike'u ${ }^{38} \mathrm{Ar}$. Badania zostały wykonane w Laboratorium Minerałów Ilastych (ClayLab) Ośrodka Badawczego w Krakowie Instytutu Nauk Geologicznych Polskiej Akademii Nauk.

\section{WYNIKI BADAŃ}

Badaniom został poddany bardzo drobnoblastyczny łupek kwarcowo-muskowitowo-chlorytowy o penetratywnej foliacji S1. Skośnie do niej wykształcony jest kliważ S2, a prostopadle S3 (ryc. 2). Foliacja metamorficzna S1jest podkreślona laminami zbudowanymi głównie z drobnoblastycznego kwarcu, muskowitu, plagioklazu i chlorytu. Mikroskopowo obok dominujących drobnoblastycznych lamin są widoczne pojedyncze, większe soczewki, które w porównaniu do otoczenia nie zawierają chlorytu. Obecność chlorytu oraz brak granatu wskazuje na niski stopień metamorfizmu badanej skały (facja zieleńcowa). Skład mineralny określono na podstawie analizy XRD (ryc. 3). Metoda ilościowa wskazuje na dominację w skale kwarcu (ok. 40\%). Muskowit stanowi ok. 25\% badanej skały, a chloryt i plagioklaz po kilkanaście procent. Wstępne datowanie K-Ar wykonano na próbkach muskowitu różnych frakcji, wyseparowanych z całej skały. Uzyskano wiek $593,1 \pm 20,2$ mln lat. W celu dokładniejszej charakterystyki wiekowej analizowanego muskowitu przygotowano separaty $\mathrm{z}$ podziałem na dwie drobniejsze frakcje: $2-0,2 \mu \mathrm{m}$ oraz $<0,2 \mu \mathrm{m}$. Odrzucono muskowit tworzący duże blaszki, o frakcji powyżej $2 \mu \mathrm{m}$, gdyż uznano że może on stanowić materiał detrytyczny. Wiek dla frakcji muskowitu o wielkości 2-0,2 $\mu$ m określono na 544,1 $\pm 13,7$ mln lat. Najdrobniejsza frakcja badanego minerału $<0,2 \mu \mathrm{m}$ dała odmienny wynik $441,1 \pm 11,7 \mathrm{mln}$ lat (tab. 1).

\section{INTERPRETACJA WYNIKÓW}

Należy sądzić, że utwory formacji Yargait znajdują się w strefie pośredniej mas wciagniętych w strefę kolizji terranu Zavkhan z terranem jeziornym. Sugeruje to potwierdzony w wyniku otrzymanych badań niski stopień metamorfizmu badanych skał, który kontrastuje do niezmetamorfizowanych skał jednostki Khasagt na północy i w stosunku do wyższego stopnia metamorfizmu wczesnoneoproterozoicznych (ok. 950 Ma; Kröner i in., 2010) amfibolitów kompleksu Zamtyn Nuruu, które odsłaniają się w oknie tektonicznym w Paśmie Zamtyn na południe od miejscowości Ałtaj. Amfibolity te reprezentują głębszy element parautochtoniczny terranu Zavkhan (Hanžl, Aichler, 2007; Lehmann i in., 2010), na który są nasunięte wysokociśnieniowe skały allochtonicznego kompleksu Tsakhir Uul należącego do terranu jeziornego (eklogity o sygnaturze MORB - Mid Ocean Ridge Basalts; Štípská i in., 2010).

Najstarsza z otrzymanych dat $-593,1 \pm 20,2 \mathrm{mln}$ lat może wynikać z wymieszania drobnoblastycznego metamorficznego muskowitu z większymi blaszkami, które występują w soczewkach. Podejrzewamy, że ten ostatni typ muskowitu może mieć pochodzenie detrytyczne, a zarazem starszą charakterystykę wiekową. 
Tab. 1. Wyniki datowań K-Ar próbki oraz frakcji

Table 1. K-Ar dating results of the sample and fractions

\begin{tabular}{|c|c|c|c|c|c|c|c|c|c|}
\hline $\begin{array}{c}\text { Próbka / } \\
\text { frakcja } \\
\text { Sample / } \\
\text { fraction }[\mu \mathrm{m}]\end{array}$ & $\begin{array}{l}\text { Nr pomiaru* } \\
\text { Measurement } \\
\quad \text { No. * }\end{array}$ & $\begin{array}{c}\text { Waga } \\
\text { Weight } \\
{[\mathrm{mg}]}\end{array}$ & $\% \mathrm{~K}_{2} \mathrm{O}$ & $\% \mathrm{~K}$ & $\%$ 40Ar* & $\begin{array}{c}\text { Wiek [Ma] } \\
\text { Age }\end{array}$ & $\begin{array}{c}\text { Bląd [Ma] } \\
\text { Uncertainty } \\
( \pm)\end{array}$ & $\begin{array}{c}\text { Wiek sumaryczny } \\
\text { [Ma] } \\
\text { Total age }\end{array}$ & $\begin{array}{c}\text { Bląd sumaryczny } \\
{[\text { Ma] }} \\
\text { Total uncertainty } \\
( \pm)\end{array}$ \\
\hline & 1 & 47,71 & 2,83 & 2,35 & 98,3 & 574,24 & 19,23 & 593,1 & 20,2 \\
\hline & 2 & & & & 57,0 & 11,72 & 0,58 & & \\
\hline & 3 & & & & 52,6 & 1,84 & 0,11 & & \\
\hline & 4 & & & & 63,6 & 3,12 & 0,15 & & \\
\hline & 5 & & & & 58,8 & 1,63 & 0,10 & & \\
\hline & 6 & & & & 51,8 & 0,52 & 0,04 & & \\
\hline \multirow[t]{2}{*}{$2,0-0,2$} & 1 & 15,76 & 5,85 & 4,86 & 96,8 & 544,05 & 13,58 & 544,1 & 13,7 \\
\hline & 2 & & & & 6,3 & 0,09 & 0,09 & & \\
\hline \multirow[t]{2}{*}{$<0,2$} & 1 & 16,00 & 5,28 & 4,38 & 92,0 & 441,03 & 11,69 & 441,1 & 11,7 \\
\hline & 2 & & & & 5,3 & 0,06 & 0,06 & & \\
\hline
\end{tabular}

* Numery pomiarów oznaczają kolejne strzelania laserem w tę samą próbkę ze stopniowo wzrastającą mocą.

* Measurement numbers represent successive laser firing at the same sample with gradually increasing power.

Kolejna z dat $-544,1 \pm 13,7 \mathrm{mln}$ lat (dla frakcji 2,0$0,2 \mu \mathrm{m})$ - jest zbliżona do momentu ekshumacji wspomnianych wyżej eklogitów, która jest datowana na $540 \mathrm{Ma}$ (Štípská i in., 2010). Na trwającą w tym czasie obdukcję terranu jeziornego na krawędź terranu Zavkhan wskazywali również Bold i in. (2016b). Data ta wskazuje na późnoediakarski metamorfizm skał w obrębie jednostki Urgamal, któremu towarzyszyło fałdowanie utworów klastycznych formacji Yargait i rozwój penetratywnej foliacji S1. Powstanie penetratywnego kliważu S2 (złupkowacenia) w obrębie metaosadowych utworów ogniwa Shar Shoroot należy wiązać z nasileniem deformacji w końcowej fazie procesów fałdowych, które mogły nastąpić przed zamknięciem basenu Tsagaan Olom w sąsiedniej jednostce Khasagt w górnym terenewie (Bold i in., 2016b; Sikora i in., 2019).

Najmłodsza z otrzymanych dat $-441,1 \pm 11,7 \mathrm{mln}$ lat (dla frakcji $<0,2 \mu \mathrm{m}$ ) - odpowiada późnoordowicko-sylurskiej regionalnej ekstensji na obszarze terranu Zavkhan (Bold i in., 2016b). Zaznaczyła się ona rozwojem sinistralnego basenu pull-apart wypełnionego osadami klastycznymi, któremu towarzyszył bimodalny (ryolitowo-bazaltowy) wulkanizm formacji Teel $(446,03 \pm 0,21 \mathrm{Ma}$; Kilian $\mathrm{i}$ in., 2016) oraz umiejscowieniem granitoidów intruzji Numrug (442,1 \pm 19 Ma; Bold i in., 2016b). Należy sądzić, że w tym czasie rozwinął się kliważ S3 w badanych skałach.

\section{PODSUMOWANIE}

Zaprezentowane wyniki analiz należy traktować jako wstęp do dalszych badań nad rekonstrukcją zdarzeń tektonicznych na SW obrzeżeniu terranu Zavkhan. Mimo że są one oparte na datowaniach jednej próbki, to wykazały dużą przydatność stosowanej metody K-Ar do określenia wieku przebudowy strukturalnej i mineralnej w skałach niskiego stopnia metamorfizmu, co uzasadnia jej zastosowanie do badań podobnych odmian skalnych w omawianym obszarze. Pozwalają one na doprecyzowanie czasowego następstwa makro- i mikrostruktur tektonicznych między jednostkami oraz na określenie wieku izotopowego różnych etapów deformacji wywołanych paleozoiczną akrecją terranów w mongolskiej części CAOB.

Badania wykonano w ramach projektu nr 62.9012.1974.00.0 finansowanego ze środków statutowych Państwowego Instytutu
Geologicznego - Państwowego Instytutu Badawczego. Autorzy artykułu dziękują Recenzentom za krytyczne podejście i cenne uwagi podnoszące jego wartość naukową. Podziękowania kierujemy również do dr Aleksandry Kozłowskiej za udostępnienie mikroskopu do badań petrograficzno-strukturalnych oraz do Zuzanny Ciesielskiej i Marioli Kowalik za wykonanie pomiarów potasu, argonu i dyfrakcji rentgenowskiej.

\section{LITERATURA}

BADARCH G., DICKSON CUNNINGHAM W., WINDLEY B.F. 2002 - A new terrane subdivision for Mongolia: Implications for the Phanerozoic crustal growth of Central Asia. J. Asian Earth Sci., 21 (1): 87-110. BOLD U., CROWLEY J.L., SMITH E.F., SAMBUU O., MACDONALD F.A. 2016a - Neoproterozoic to early Paleozoic tectonic evolution of the Zavkhan Terrane of Mongolia: implications for continental growth in the Central Asian Orogenic Belt. Lithosphere, 8: 729-750.

BOLD U., SMITH E.F., ROONEY A.D., BUCHWALDT R., RAMEZANI J., SCHRAG D.P., MACDONALD F.A. 2016b - Neoproterozoic stratigraphy of the Zavkhan Terrane of Mongolia: The backbone for Cryogenian and Early Ediacaran chemistratigraphic records. Am. J. Sci., 316: 1-63.

BURASHNIKOV V.V. 1990 - Tectonics of the Urgamal zone, early Caledonides of western Mongolia [PhD Thesis]: Rus. Acad. Sci., Moscow, Russia.

CLAUER N., ZWINGMANN H., LIEWIG N., WENDLING T. 2012 Comparative $40 \mathrm{Ar} / 39 \mathrm{Ar}$ and $\mathrm{K}-\mathrm{Ar}$ dating of illite-type clay minerals: A tentative explanation for age identities and differences. Earth Sci. Rev., 115: 76-96.

COCKS L.R.M., TORSVIK T.H. 2007 - Siberia, the wandering northern terrane, and its changing geography through the Palaeozoic. Earth Sci. Rev., 82: 29-74.

Constraints on the evolution of the Mongol-Okhotsk Ocean, suture and orogen. J. Geol. Soc., 162 (1): 125-134.

DON J., DUMICZ M. 1964 - Budowa geologiczna południowej części obszaru górskiego Chasagtu-Chairchan-Uł w zachodniej Mongolii. Rocz. PTG, 34 (4): 589-596.

DUMICZ M., DON J. 1970 - Formacja diabazowo-klastyczna w Chasagtu-Chajrchan-ula i Chan-Tajsziri-nuru. Biul. Inst. Geol., 226 (2): 199-225.

ENKHBAYAR B., BATBOLD D., MONHNASAN CZ., SUMHUU D., OHIRHUAYAT CZ., BARSBOLD C. 2005 - Govi-Altaj ajmagijn Bayan Uul, Jargalan sumdin nutagt 2003-2004 (sheets L-46-47 A, B, W, G L-46-48 A, B). Archive of Mineral Resources and Petroleum Authority of Mongolia, Ulaan-Baatar, $\mathrm{n}^{\circ} 5660$ (in Mongolian).

FITZ-DIAZ E., VAN DER PLUIJM B. 2013 - Fold dating: A new Ar/Ar illite dating application to constrain the age of deformation in shallow crustal rocks. J. Structural Geol., 54: 174-179.

HANž L P., AICHLER J. 2007 - Geological survey of the Mongolian Altay at a scale 1:50,000 (Zamtyn nurru-50). Prague, Czech Republic, Czech Geological Survey, Final Report.

KILIAN T.M., SWANSON-HYSELL N.L., BOLD U., CROWLEY J., MACDONALD F.A. 2016 - Paleomagnetism of the Teel basalts from the 
Zavkhan terrane: Implications for Paleozoic paleogeography in Mongolia and the growth of continental crust. Lithosphere, 8 (6): 699-715.

KOWALSKA S. 2012 - Granica diageneza/anchimetamorfizm w skałach najwyższego proterozoiku i kambru ze wschodniej części bloku małopolskiego wyznaczona na podstawie badań minerałów ilastych. Pr. Nauk. Inst. Nafty i Gazu, 187: 1-153.

KOZAKOV I., YARMOLYUK V., KOVACH V., BIBIKOVA E., KIRNOZOVA T., KOZLOVSKII A., PLOTKINA Y.V., FUGZAN M., LEBEDEV V., ERDENEZHARGAL C. 2012 - The Early Baikalian crystalline complex in the basement of the Dzabkhan microcontinent of the Early Caledonian orogenic area, Central Asia. Stratigraph. Geol. Correlat., 20: 231-239.

KRÖNER A., KOVACH V., BELOUSOVA E., HEGNER E., ARMSTRONG R., DOLGOPOLOVA A., SELTMANN R., ALEXEIEV D. HOFFMANN J., WONG J. 2014 - Reassessment of continental growth during the accretionary history of the Central Asian Orogenic Belt. Gondwana Res., 25: 103-125.

KRÖNER A., LEHMANN J., SCHULMANN K., DEMOUX A., LEXA O., TOMURHUU D., ŠTÍPSKÁ P., LIU D., WINGATE M.T.D. 2010 Lithostratigraphic and geochronological constraints on the evolution of the Central Asian orogenic belt in SW Mongolia: Early Paleozoic rifting followed by late Paleozoic accretion. Am. J. Sci., 310: 523-574. LEHMANN J., SCHULMANN K., LEXA O., CORSINI M., KRÖNER A., ŠTÍPSKÁ P., TOMURHUU D., OTGONBATOR D. 2010 - Structural constraints on the evolution of the Central Asian orogenic belt in SW Mongolia. Am. J. Sci., 310: 575-628.

MACDONALD F.A., JONES D.S., SCHRAG D.P. 2009 - Stratigraphic and tectonic implications of a newly discovered glacial diamictite-cap carbonate couplet in southwestern Mongolia. Geology, 37: 123-126.

MOSSAKOVSKY A., RUZHENTSEV S., SAMYGIN S., KHERASKOVA T. 1994 - Central Asian fold belt: Geodynamic evolution and formation history. Geotectonics, 27: 445-474.

ODIN G.S. (red.) 1982 - Numerical dating in stratigraphy. John Wiley \& Sons.

RUTKOWSKI E. 1970 - Geologia Chasagtu-Chajrchan-uła. Biul. Inst. Geol., 226: 51-154

RUZHENTSEV S.V., BURASHNIKOV V.V. 1996 - Tectonics of the western Mongolian Salairides. Geotectonics, 29: 379-394.

ŞENGÖR A., NATALIN B., BURTMAN V. 1993 - Evolution of the Altaid tectonic collage and Palaeozoic crustal growth in Eurasia. Nature, 364 299-307.

SIKORA R. 2015 - Wyniki badań i mezoskopowa analiza tektoniczno-strukturalna w rejonie Hasagt. [W:] Wójcik i in., Raport z prac geologicznych przeprowadzonych w rejonie Hasagt (Mongolia) w latach 2009-2013. Nar. Arch. Geol. Państw. Inst. Geol., nr arch. I:3319/2021, Warszawa.

SIKORA R., MADEJ S., WÓJCIK A., NESCIERUK P. 2016 - Deformation structures of the Mesoproterozoic and the Neoproterozoic-Cambrian rocks of the Khasagt Massif (Western Mongolia) in the light of meso- and microstructural analysis. [W:] Wojewoda J. (red.), Wyzwania Polskiej Geologii. 3. Polski Kongres Geologiczny, 14-18 września 2016 Wrocław. Abstrakty: 344-345.

SIKORA R., WÓJCIK A., BAZARNIK J. 2019 - Concepts of tectonic evolution of SW margin of the Zavkhan terrane in the Khasagt Mountains
(Western Mongolia) - review. [W:] Hrdličková K., Daňková L. (red.), $17^{\text {th }}$ Meeting of the Central European Tectonic Groups, 24-26 April 2019, Rozdrojovice. Abstract Volume: 69.

SIKORA R., WÓJCIK A. 2017 - Fold and thrust events on the SW margin of the Zavkhan terrane (Western Mongolia) - implications for accretionary history of the Central Asian Orogenic Belt (CAOB). Acta Mineralogica-Petrographica, CETEG 2017 Abstract Volume, Pre- and Post-Conference Field Trip Guide, 32: 37.

SMITH E.F., MACDONALD F.A., PETACH T.A., BOLD U., SCHRAG D.P. 2016 - Integrated stratigraphic, geochemical and paleontological late Ediacaran to early Cambrian records from southwestern Mongolia. Geol. Soc. Am. Bull., 128: 442-468.

ŠTÍPSKÁ P., SCHULMANN K., LEHMANN J., CORSINI M., LEXA O., TOMURHUU D. 2010 - Early Cambrian eclogites in SW Mongolia: evidence that the Palaeo-Asian Ocean suture extends further east than expected. J. Metamorph. Geol., 28: 915-933.

TOGTOKH D., BAATARKHUYAG A., BAYARDALAI S. 1995 - The

Report of Result of the Geological Grouped Mapping: Ulaanbaatar, Mongolia, Mineral Resources Authority of Mongolia, scale $1: 200,000$. TOMURTOGOO O., WINDLEY B., KRÖNER A., BADARCH G., LIU D. 2005 - Zircon age and occurrence of the Adaatsag ophiolite and Muron shear zone, central Mongolia: constraints on the evolution of the Mongol-Okhotsk ocean, suture and orogen. J. Geol. Soc., 162: 125-134.

VAN DER VOO R., VAN HINSBERGEN D.J.J., DOMEIER M., SPAKMAN W., TORSVIK T.H. 2015 - Latest Jurassic-earliest Cretaceous closure of the Mongol-Okhotsk Ocean: A paleomagnetic and seismological tomographic analysis. [W:] Anderson T.H., Didenko A.N., Johnson C.L., Khanchuk A.I., MacDonald J.H., Jr. (red.), Late Jurassic Margin of Laurasia - A Record of Faulting Accommodating Plate Rotation. Geol. Soc. Am. Spec. Pap., 513: 589-606.

WILHEM C., WINDLEY B.F., STAMPFLI G.M. 2012 - The Altaids of Central Asia: A tectonic and evolutionary innovative review. Earth Sci. Rev., 113: 303-341.

WINDLEY B.F., ALEXEIEV D., XIAO W., KRÖNER A., BADARCH G. 2007 - Tectonic models for accretion of the Central Asian orogenic belt. J. Geol. Soc., London, 64: 31-47.

WÓJCIK A., SIKORA R., KRZEMIŃSKA E., MIKULSKI S., NESCIERUK P. 2019 - New data on the age magmatic rocks in the Khasagt Mts (Zavkhan terrane, western Mongolia. [W:] Hrdličková K., Daňková L. (red.), $17^{\text {th }}$ Meeting of the Central European Tectonic Groups, 24-26 April 2019, Rozdrojovice. Abstract Volume: 94.

WÓJCIK A., SIKORA R., NESCIERUK P., WÓDKA M., KAMIENIARZ S. 2015 - Wyniki badań geologiczno-kartograficznych reambulowanych map geologicznych wykonanych przez geologów mongolskich. [W:] Wójcik i in., Raport z prac geologicznych przeprowadzonych w rejonie Hasagt (Mongolia) w latach 2009-2013. Nar. Arch. Geol. Państw. Inst. Geol., I:3319/2021, Warszawa.

ZHAO Y., SONG B., ZHANG S.H. 2006 - The Central Mongolian microcontinent: Its Yangtze affinity and tectonic implications: Proceedings Symposium on continental growth and orogeny in Asia. Taipei, Taiwan: 135-136.

Praca wpłyneła do redakcji 1.04.2021 r. Akceptowano do druku 1.06.2021 r. 